\title{
NASA looks to extended balloon flights
}

[WASHINGTON] The US National Aeronautics and Space Agency (NASA) hopes within the next few years to begin scientific balloon flights of up to 100 days duration as a way of conducting near-space research at a fraction of current launch costs.

The so-called Ultra-Long Duration Balloons would carry payloads of 2,000 kg or more, including about a tonne of scientific instruments. They would typically circle the globe at altitudes of $40 \mathrm{~km}$, high enough for astronomical observations as well as studies of the stratosphere.

NASA already launches 20 to 30 scientific balloons each year, including a few longduration flights. But balloons can at present stay aloft for only a couple of weeks.

The new, much larger 'superpressure' balloons would be made of advanced plastics such as Mylar or polyethylene, with a lightweight lamination to add strength. The lamination techniques were pioneered in sails for racing yachts.

Several tests of the superpressure balloons are scheduled in the next two years, and NASA plans a demonstration flight, with a scientific payload, in the year 2000 . Six candidate experiments were selected last April, one of which will be chosen this winter for the flight. If the demonstration is successful, regular 100-day flights could begin in 2001.

Such flights would be "almost like a satel-

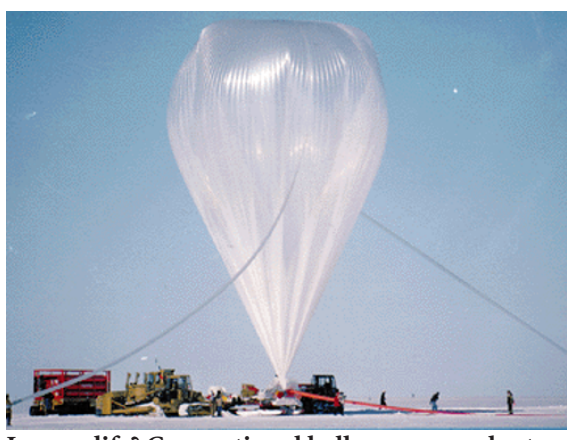

Longer life? Conventional balloons can only stay up for a couple of weeks before losing pressure.

lite" for some kinds of research, says Jack Tueller, balloon-project scientist at NASA's Goddard Space Flight Center in Maryland. High-altitude balloons are ideal platforms for infrared and $\gamma$-ray astronomy, and for studies of the cosmic microwave background.

And balloon experimenters usually get their scientific payload back, says Tueller. Their instruments can also have a wider variety of shapes and sizes, as they do not have to fit within the launch shroud of a rocket. Launch costs are another advantage of scientific balloons. A typical mission can launch for under $\$ 1$ million, says Tueller, compared with up to $\$ 18$ million using a Pegasus rocket .

NASA is working on designs for a 'ballooncraft' with standardized subsystems to provide power, communications and other essentials to scientific instruments on 100-day flights, which would further reduce development costs.

The technical obstacles facing superpressure balloons are thought to be fairly straightforward, but the programme still faces political barriers. Tueller says the 100day flights would probably launch from the Southern Hemisphere at first, largely for political reasons.

Circumnavigating the globe in midnorthern latitudes would require overflight permission from many countries, including Libya and Iraq. Missions flying at higher northern latitudes would pass over Russia, which has not yet agreed to allow such flights.

Safety issues will also have to be resolved before the balloon programme gets under way. Balloon payloads have been known to fall to the ground, and Tueller concedes that scientists would face a greater risk of losing their instruments during a 100-day flight than on shorter missions.

NASA intends to begin almost immediately to take advantage of this cheap way of reaching the edge of space. The agency will soon be looking for low-cost space missions for its University Explorer programme, and will for the first time include the option of flying instruments on long-duration (10-20day) balloon flights as well as on satellites or the space shuttle.

TonyReichhardt

\section{Female scientists wanted - apply to UK research councils}

[LONDON] Britain's six research councils are to keep a close eye on the relative success of men and women applying for grants and fellowships. The move coincides with the revelation that, although success rates are similar, there is clear evidence that a higher proportion of male than female academics apply for research awards.

Margaret Beckett, the President of the Board of Trade and as such, the cabinet minister responsible for science, said last week that she has asked the director-general of research councils, Sir John Cadogan, to report annually on the success rates of women in obtaining grants and fellowships.

Beckett holds a degree in metallurgy and worked briefly as a researcher before entering politics. Speaking at the annual meeting of the pressure group Save British Science, she said she was determined to encourage more women to enjoy a scientific career. "We run the risk of wasting the talents of half the population," she warned.

But she also said that it is necessary to ensure that women work in a fair and unbiased environment, adding that there had been "some disquiet" over a recent study of the competition for fellowships at the
Swedish Medical Research Council which revealed bias in favour of male candidates (see the Commentary by Wennerås and Wold, Nature 387, 341-343; 1997).

According to Beckett, a survey of success rates in British research councils carried out after the publication of the Swedish data did not reveal a similar pattern, the rates between the two sexes being "very similar".

Last year, for example, 24 per cent of male grant applicants to the Biotechnology and Biological Sciences Research Council, and 26 per cent to the Medical Research Council (MRC), were successful; equivalent rates for female candidates were 19 and 29 per cent.

Similar conclusions are revealed in a survey, Women and Peer Review, published this week by the Wellcome Trust's Unit for Policy Research in Science and Medicine. Also prompted by the Swedish study, the Wellcome survey concludes that there is "no evidence of sex discrimination" in the award of the trust's project or programme grants, or its senior research fellowships.

But both the Wellcome survey and a parallel survey by the MRC reveal that women do not apply for awards in the proportions that would be expected from the number of female academics working in British universities (see Correspondence, page 438 ).

In the case of Wellcome, five times as many men as women applied to the trust, even though there were only marginally more male academic biomedical staff than female in the academic year 1995-96 (indeed, in the under- 25 age group, there were 50 per cent more female biomedical academics than male). Similar statistics emerge from the MRC survey; only 21.3 per cent of applicants for programme grants were women.

The surveys' authors offer no explanations. But they recommend that research funding bodies should, as part of their efforts to ensure equal opportunities, work together to investigate the factors that may prevent women from applying for grants in the expected numbers.

Officials at the Department of Trade and Industry point out that efforts to redress the sex balance in research include the Dorothy Hodgkin fellowships, introduced by the Royal Society in 1995. They also argue that the new concordat for contract research should enable more women to remain longer in the academic community. David Dickson 